\title{
Intradermal B.C.G. Vaccination by Jet Injection
}

\author{
MARGARET I. GRIFFITHS,* M.D., M.R.C.P., D.C.H. ; M. C. DAVITT, $\dagger$ M.B., CH.B. ; \\ T. W. BRINDLE, $\ddagger$ M.B., CH.B., D.P.H. ; T. HOLME, $\ddagger$ M.B., CH.B., D.P.H. ;
}

Brit. med. F., 1965, 2, 399-401

Intradermal vaccination with B.C.G. has been an accepted prophylactic measure against tuberculosis in Great Britain since 1950. When given to schoolchildren it has been shown consistently to produce tuberculin sensitivity (Miller and Kinsley, 1961), to protect against tuberculosis (Sutherland, 1959; Medical Research Council, 1963), and to be relatively free from complications (Medical Research Council, 1958). The intradermal method is still the most accurate and reliable means of administering B.C.G. vaccine. It has, however, disadvantages in that considerable skill is required if subcutaneous inoculation is to be avoided; highly trained vaccinators need to spend a long time over the injections, and the fact that a needle has to be inserted into the skin makes the technique unacceptable to many schoolchildren and unsophisticated adults. Progress in B.C.G. vaccination techniques must therefore be towards efficiency combined with simplicity, and a search is still continuing for a method which is accurate and effective, which causes few complications, which requires little skill in administration, and which is economical in manpower and materials.

Jet injection, if it could be adapted to administer a small amount of vaccine strictly intradermally, would obviously supply this need. The Dermo-jet ${ }^{1}$ injector was developed for the intradermal injection of approximately $0.1 \mathrm{ml}$. of local anaesthetic (Krantz, 1960) into the skin, and its use has since been described in the production of dental analgesia (Stephens and Kramer, 1964) and in the treatment of herpetic skin lesions (Juel-Jensen and MacCallum, 1965). It seemed to us that this instrument might provide a method of administering B.C.G. vaccine which would be painless and rapid, and be highly acceptable to the recipients. The aim of this short paper is to draw attention to the advantages of such a technique.

A jet injector (Dermo-jet) intended for dental use (for injection of local anaesthetic into the alveolar mucous membrane) was first employed by one of us (M. I. G.) in the summer of 1963 , but the force of the jet was found to be inadequate for penetration of the skin, vaccination was not successful, and the method was temporarily abandoned.

Shortly afterwards another member of the team (M. J. D.) obtained an injector with a stronger compression spring and found that intradermal weals could be produced in the skin of the deltoid region with a fair degree of reliability. Several hundred schoolchildren in Manchester were vaccinated by this method, and, judged by the production of a local weal, it appeared to be successful. At this time no follow-up by tuberculin-testing was undertaken, and no comparison with concurrent intradermal vaccination could be made.

It was then decided to institute a trial of this method of vaccination, and to compare it with intradermal vaccination, in schoolchildren in Manchester, South Staffordshire, and some health divisions of Cheshire.

\section{Materials and Methods}

All vaccinations and tuberculin tests were carried out by us in the areas designated.

The jet injectors used were standard Dermo-jets (Fig. 1) fitted with springs of compression power as recommended by the manufacturer.
Schoolchildren aged 11 to 13 years who presented for vaccination were tuberculin-tested either by Mantoux-testing with 10 T.U. P.P.D. or by Heaf-testing with Protoderm ${ }^{2}$ P.P.D. containing 100,000 T.U./ml. The tests were read after 72

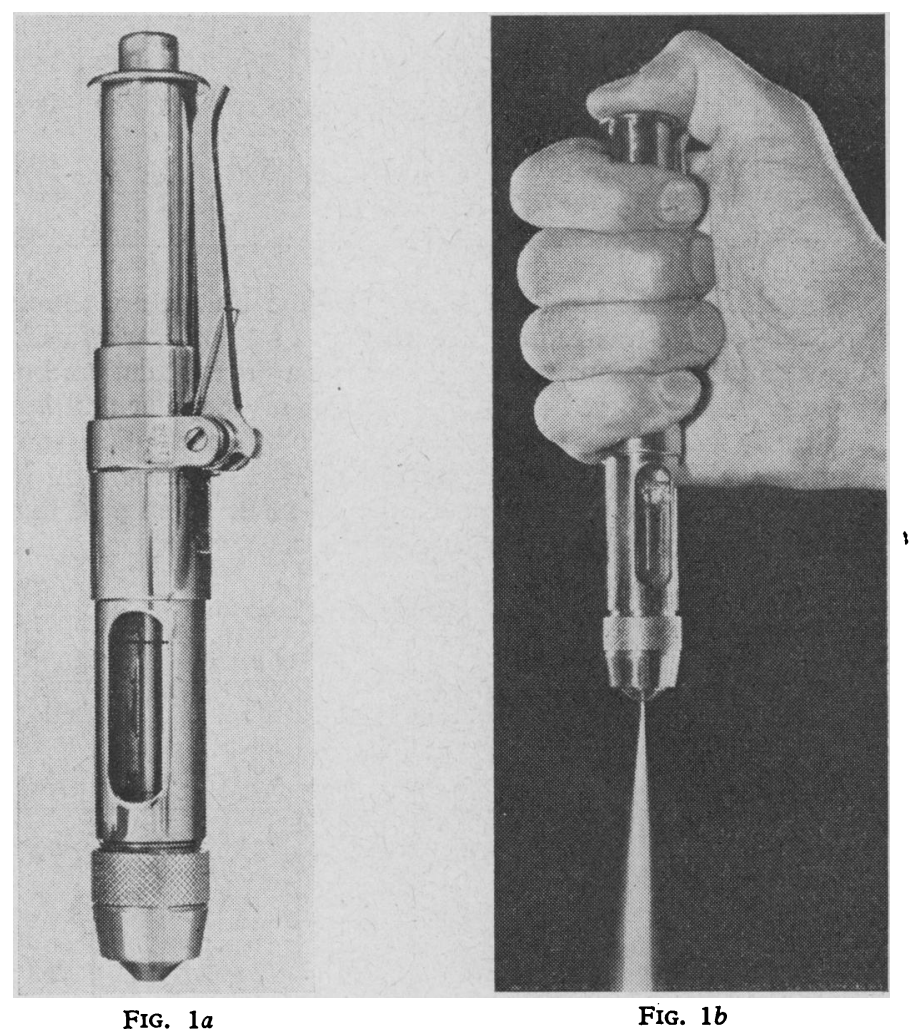

FIG. 1.-The Dermo-jet injector.

hours and seven days respectively. The potency of the P.P.D. used was carefully checked and the dilute material for Mantoux-testing was replaced every two weeks.

All children who produced a negative reaction to tuberculin were vaccinated alternately either by the intradermal injection of $0.1 \mathrm{ml}$. of freeze-dried B.C.G. vaccine (Glaxo) containing between $4 \times 10^{6}$ and $9 \times 10^{6}$ viable bacilli per $\mathrm{ml}$. or by one shot of the same batch of vaccine administered by the Dermo-jet. Mantoux tuberculin-testing (10 T.U. P.P.D.) was carried out 6 to 10 weeks later and the results were read in 72 hours without the operator knowing by which method the injection had been given. The intensity of the tuberculin reaction was recorded in millimetres of induration by taking the mean of - two diameters. The size and type of the local vaccination lesions were recorded at the same time.

* Institute of Child Health, Birmingham University, and Staffordshire County Council Health Department.

+ Manchester Corporation Health Department.

¥ Divisional Medical Officer, Cheshire County Council.

Schuco International London Ltd., 46 Ravensdale Avenue, London N.12.

${ }^{2}$ Allen and Hanburys, Bethnal Green, London. 


\section{Results}

The results of tuberculin-testing are shown in Table I. A total of 784 children received the ordinary intradermal vaccination and 770 were successfully vaccinated ; 758 children were vaccinated with the pressure-jet gun, 737 successfully.

TABLE I.-Results of Tuberculin-testing with 10 T.U. of P.P.D.

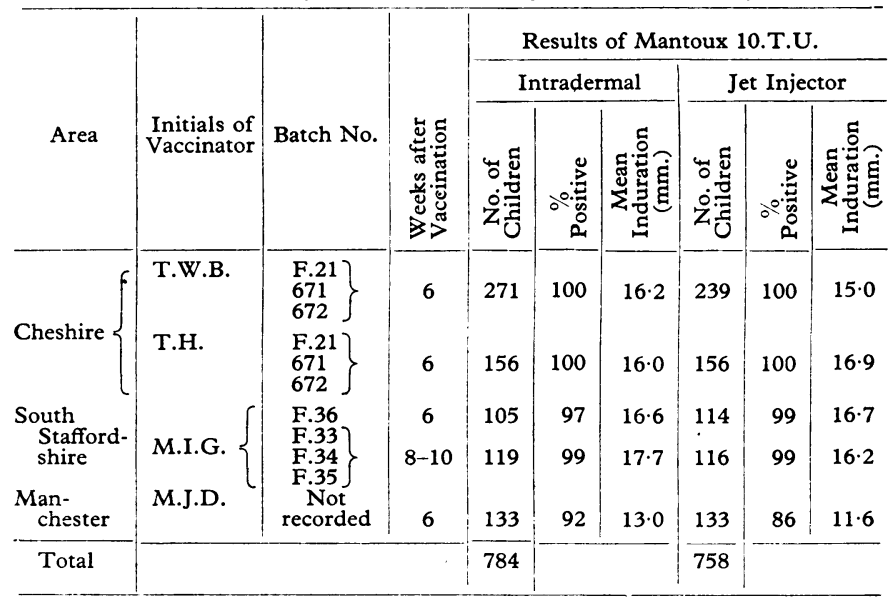

The sizes of the local B.C.G. vaccination lesions are shown in Table II. It was found that there was a wider variation in diameter in the lesions produced by Dermo-jet inoculation, but that the lesions tended to be more frequently papular and less frequently vesicular than those produced by inoculation with a syringe. The occasional larger papules (11 or more $\mathrm{mm}$. in diameter) were often below the skin, and made us suspect that the injection may have been subcutaneous.

\begin{tabular}{|c|c|c|c|c|c|c|c|}
\hline \multirow{3}{*}{ Area } & \multirow{3}{*}{$\begin{array}{c}\begin{array}{c}\text { Initials } \\
\text { of } \\
\text { Vaccinator }\end{array} \\
\text {. }\end{array}$} & \multirow{3}{*}{$\begin{array}{l}\text { Batch } \\
\text { No. }\end{array}$} & \multirow{3}{*}{$\begin{array}{l}\text { Weeks } \\
\text { after } \\
\text { Vac- } \\
\text { cination }\end{array}$} & \multicolumn{4}{|c|}{ Size of Vaccination Lesion } \\
\hline & & & & \multicolumn{2}{|c|}{ Intradermal } & \multicolumn{2}{|c|}{ Jet Injector } \\
\hline & & & & $\begin{array}{l}\text { No. of } \\
\text { Children }\end{array}$ & $\begin{array}{c}\text { Mean } \\
\text { Size } \\
(\mathrm{mm} .)\end{array}$ & $\begin{array}{l}\text { No. of } \\
\text { Children }\end{array}$ & $\begin{array}{c}\text { Mean } \\
\text { Size } \\
(\mathrm{mm} .)\end{array}$ \\
\hline \multirow{2}{*}{ Cheshire } & T.W.B. & $\left.\begin{array}{l}\text { F.21 } \\
671 \\
672\end{array}\right\}$ & 6 & 271 & $5 \cdot 3$ & 239 & $5 \cdot 1$ \\
\hline & Т.H. & $\left.\begin{array}{l}\text { F.21 } \\
671 \\
672\end{array}\right\}$ & 6 & 156 & $6 \cdot 0$ & 156 & $7 \cdot 2$ \\
\hline \multirow{2}{*}{$\begin{array}{l}\text { South } \\
\text { Stafford- } \\
\text { shire }\end{array}$} & & $\begin{array}{l}\text { F.36 } \\
\text { F.33 }\end{array}$ & 6 & 105 & $7 \cdot 1$ & 114 & $7 \cdot 3$ \\
\hline & M.I.G. \{ & $\left.\begin{array}{l}\text { F. } 33 \\
\text { F. } 35\end{array}\right\}$ & $8-10$ & 119 & $7 \cdot 5$ & 116 & 6.7 \\
\hline
\end{tabular}

The jet method of inoculation was found to be highly acceptable to schoolchildren. Because no needles were used emotional reactions to the injection were almost eliminated, no pain was experienced, and the time taken in giving the inoculation by Dermo-jet was only about one-half of that needed for an inoculation by syringe. In continual usage, subsequent to the trial reported here, we have found that the use of the Dermo-jet enabled the number of children vaccinated at one session to be approximately doubled. A considerable saving in time was thus achieved. In addition, since no needles were introduced into the skin, the risk of transmitting hepatitis virus was avoided without having to sterilize the injection apparatus (which held approximately 50 shots) between injections.

\section{Observations on Technique}

Successful intradermal vaccination with B.C.G. depends upon the introduction into the deeper layers of the dermis of an optimum number of viable bacilli. As injection by Dermojet is an attempt to standardize this method it was found necessary to ensure $(a)$ the correct depth of penetration of the jet, and (b) the correct dosage of viable bacilli in each "shot."

Depth of penetration depends on (a) the force of the jet, which is controlled by the spring-pressure of the instrument and remains constant, and $(b)$ several variable factors in the method of firing the jet injector, illustrated in Fig. 2. If the injector was fired at right angles to the skin and held too close (Fig. 2, i) the jet penetrated too deeply and the resulting injection was subcutaneous. If the instrument was held tangentially and fired on to stretched skin (Fig. 2, ii) or fired

\section{DIAGRAM OF ACTION OF JET INJECTOR}

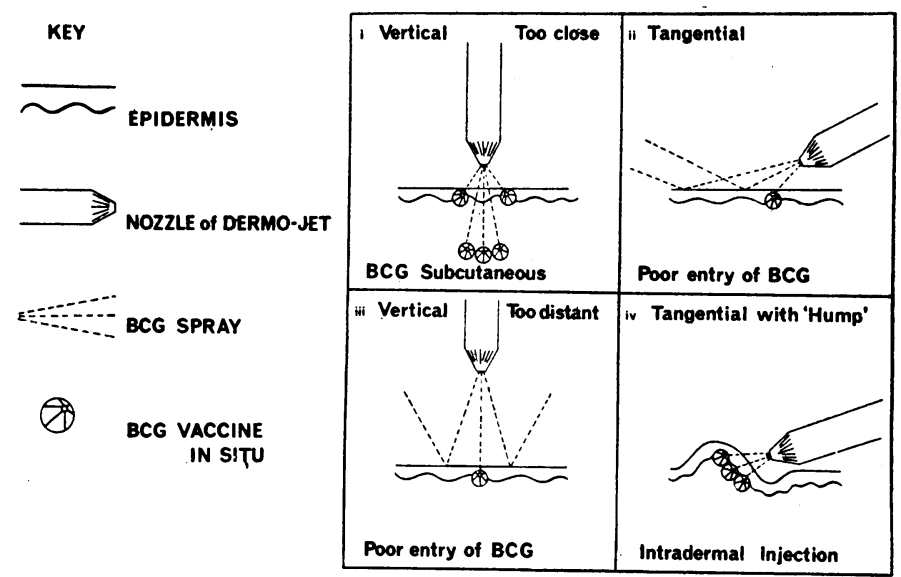

FIG. 2.-Methods of injection with jet injector.

RESULTS OF IOT.U. 6 WEEKS AFTER VACCINATION STAFFORDSHIRE CHESHIRE DERMO-JET
SUSPENDED in $5 \mathrm{ml}$.

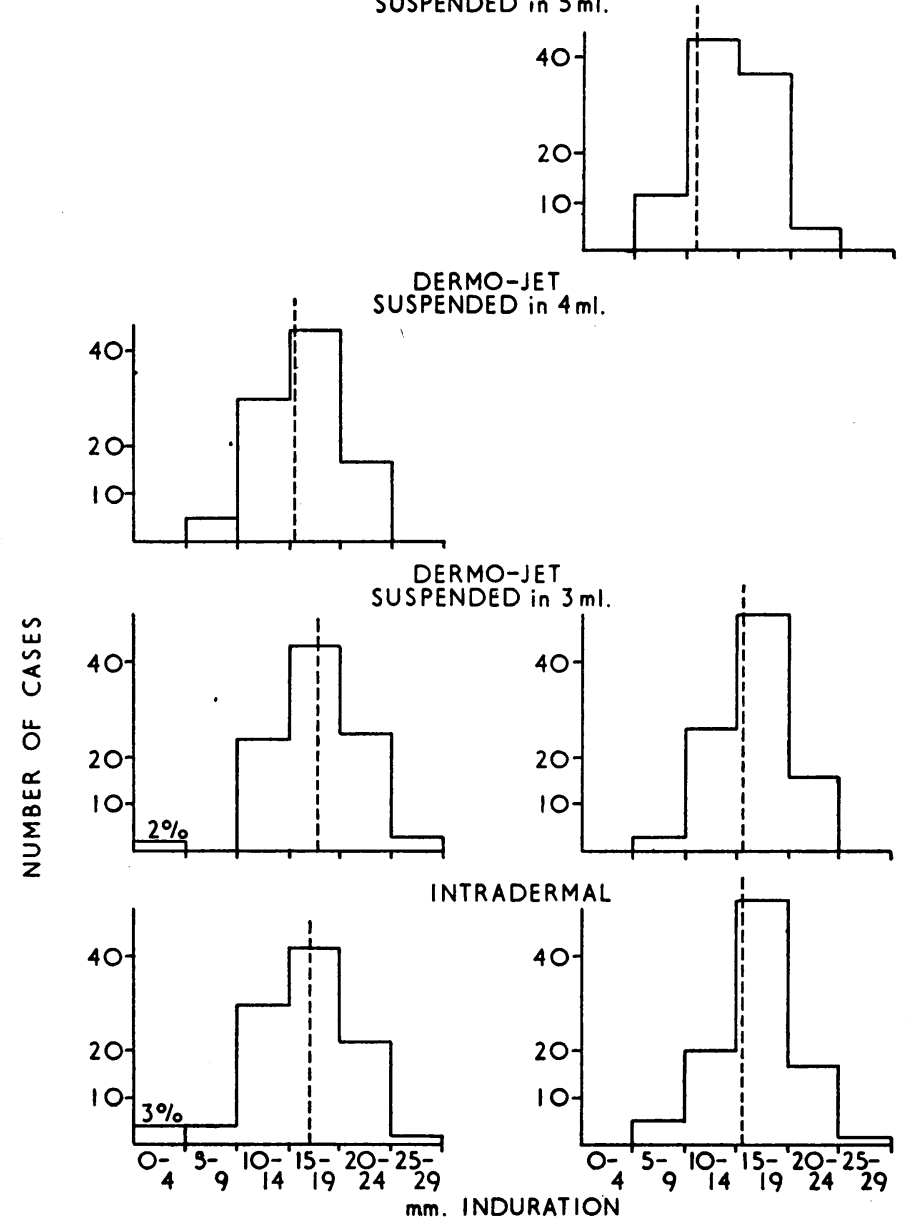

FIG. 3.-Effect of varying concentration of vaccine for Dermo-jet injection, using same batch of vaccine as for intradermal injection. Mean induration (mm.). 
vertically from too great a distance (Fig. 2, iii) penetration of the skin was inadequate. The correct depth of injection was achieved (Fig. 2, iv) by pushing up a small "hump" of skin in front of the nozzle when the gun was fired at an angle of 30 to 45 degrees to the skin. A weal approximately $5-8 \mathrm{~mm}$. in diameter could always be seen when the vaccine had been correctly given. A smaller or an absent weal was not taken as an indication for a second "shot."

Correct Dosage.-The amount of fluid fired from each gun at each shot remained constant; but it was always less than $0.1 \mathrm{ml}$. in volume, and was found to average 0.06 to $0.08 \mathrm{ml}$. with the instrument used. A dose of vaccine equivalent to that in $0.1 \mathrm{ml}$. given intradermally could be administered by suitably adjusting the amount of sterile water or saline-for example, by using $3 \mathrm{ml}$. of suspension for a $5-\mathrm{ml}$. ampoulein which the dried vaccine was resuspended, and when this procedure was adopted highly satisfactory results were obtained (Fig. 3).

\section{Summary}

A method of rapid, painless, automatic, and effective intradermal B.C.G. vaccination with the Dermo-jet injector is described.
A total of 758 schoolchildren were vaccinated by this method at the same time as 784 children who were vaccinated by the intradermal technique with the same batches of vaccine as controls.

The results of intradermal jet vaccination were satisfactory as compared with those of the usual method of intradermal vaccination.

We wish to thank the Medical Officers of Health concerned-Dr. Arnold Brown (Cheshire), Dr. Metcalfe Brown (Manchester), and Dr. G. Ramage (Staffordshire)-for allowing this investigation to be carried out and for their encouragement and interest.

The B.C.G. vaccine and tuberculin used in the trial were supplied by Glaxo Laboratories Limited, and we are grateful to Drs. J. Ungar and P. W. Muggleton for their practical help and advice throughout the trial.

\section{REFERENCES}

Juel-Jensen, B. E., and MacCallum, F. O. (1965). Brit. med. F., 1, 901. Krantz, A. (1960). Münch. med. Wschr., 102, 2034. Medical Research Council (1958). Brit. med. F., 1, 79. (1963). Ibid., 1, 973.

Miller, C. L., and Kinsley, B. J. (1961). Ibid., 2, 1322.

Stephens, R. R., and Kramer, I. R. H. (1964). Brit. dent. F., 117, 465. Sutherland, I. (1959). Tubercle (Lond.), 40, 413.

\title{
Controlled Trial of Chlormethiazole in Treatment of the Alcoholic Withdrawal Phase
}

\author{
M. M. GLATT,* M.D., D.P.M. ; H. R. GEORGE, $\dagger$ M.B., D.P.M. ; E. P. FRISCH, $\ddagger$ M.D.
}

Brit. med. F., 1965, 2, 401-404

Every year approximately 150 alcoholic patients are admitted to the alcoholic unit of St. Bernard's Hospital. A very large percentage of the patients are still intoxicated on arrival after a drinking bout, and their treatment therefore presents three different needs : to dry out the patients with as little inconvenience as possible; to discover and treat any complicating physical or psychiatric conditions; and to make the patient accept alcoholism as one of his basic problems and to help him overcome it by a long-term treatment and rehabilitation programme (Glatt, 1955).

The present report is concerned with the first type of therapy - that is, treatment of acute alcoholic intoxication and of withdrawal symptoms directly after the patient's admission. This treatment is most urgently needed during the first days of admission, when immediate withdrawal of alcohol may lead to pronounced symptoms. For the purpose of relieving the patient's psychomotor agitation, a number of drugs with sedative and tranquillizing properties have been used over the years at our alcoholic units. Most of these substances were thought to be of value when assessed clinically. However, when controlled trials were carried out with some of them-chlorpromazine, promazine, reserpine-their effect was not significantly better statistically than that of the placebo (Glatt, 1959).

Some time ago a new sedative, chlormethiazole (Heminevrin), was brought to our attention, and we used it for about one year as a routine treatment during the acute stage of alcoholic intoxication. The results of this pilot study were promising, and it was thought worth while to attempt to find out if this

* Consultant Psychiatrist, St. Bernard's Hospita', Southall, Middlesex. + Senior Registrar, St. Bernard's Hospital, Southall, Middlesex. ‡epartment of Medical Research, A.B. Astra, Sweden. experience could be confirmed in a controlled clinical trial. This attempt was likely to be still more interesting, as hitherto no controlled investigations on the effect of the drug had been available.

\section{Previous Reports}

Charonnat et al. (1953) found that the shock-producing effect of intravenously injected vitamin $B_{1}$ was related to the pyrimidine part of this molecule (Fig. 1). The thiazole part of the molecule, on the other hand, had a protective effect against convulsions induced by the pyrimidine fraction. The pharmacological properties of a number of derivatives of the thiazole fraction were investigated, and chlormethiazole, which is the ethandisulphonate of 4-methyl-5- $\beta$-chlorethyl-thiazole (Fig. 1) was found to possess the most pronounced sedative and anticonvulsive effect (Charonnat et al., 1956, 1957a, 1957b, 1958).

In rabbits and mice the substance showed anticonvulsive, sedative, and, in higher dosage, hypnotic effects (Charonnat et al., 1957a, 1958). In mice the $\mathrm{LD}_{50}$ was found to be about 20 times lower than that of pentobarbitone (Charronat et al., 1957b), and no teratogenic effect was observed in rats (Z. Hadidian and E. R. Smith, personal communication, 1963). Oral absorption of chlormethiazole is rapid and most of it is excreted in the urine within three hours (Allgen et al., 1963).

A comprehensive review of the pharmacology of chlormethiazole has been published by Svedin (1963).

In man the intravenous infusion or oral administration of chlormethiazole rapidly induces sedation, and in higher dosage sleep, which initially is deep, with muscle relaxation and miosis, 